Research Article

\title{
Comparison of Diazinon Toxicity to Temperate and Tropical Freshwater Daphnia Species
}

\author{
Thanh-Luu Pham ${ }^{1}$ and Ha Manh Bui (iD) ${ }^{2}$ \\ ${ }^{1}$ Institute of Research and Development, Duy Tan University, Da Nang, Vietnam \\ ${ }^{2}$ Department of Environmental Science, Saigon University, 273 An Duong Vuong Street, District 5, Ho Chi Minh city, Vietnam \\ Correspondence should be addressed to Ha Manh Bui; manhhakg@yahoo.com.vn
}

Received 12 June 2018; Revised 16 August 2018; Accepted 19 September 2018; Published 11 November 2018

Guest Editor: Gassan Hodaifa

Copyright ( 2018 Thanh-Luu Pham and Ha Manh Bui. This is an open access article distributed under the Creative Commons Attribution License, which permits unrestricted use, distribution, and reproduction in any medium, provided the original work is properly cited.

\begin{abstract}
The presence of pesticides in water bodies presents unique challenges to the ecosystem and all the life forms. Biological methods have been widely used to examine the toxic effects of various toxicants including pesticides. The present study aims at determining the adverse effects of diazinon, a nonsystemic organophosphate insecticide, on two cladoceran species including the temperate Daphnia magna (D. magna) and the tropical Daphnia lumholtzi (D. lumholtzi). The $48 \mathrm{~h} \mathrm{LC} \mathrm{L}_{50}$ values demonstrated higher toxicity of diazinon for D. lumholtzi at a concentration of $3.41 \mu \mathrm{g} \cdot \mathrm{L}^{-1}$ compared to D. magna at a concentration of $4.63 \mu \mathrm{g} \cdot \mathrm{L}^{-1}$. After 14 days of exposure to diazinon, the survival capacity as well as the reproduction potential of the two cladoceran species clearly reduced and their rate of population increase (RPI) decreased at concentrations $>0.1 \mu \mathrm{g} \cdot \mathrm{L}^{-1}$. The present study indicated that the tropical cladoceran $(D$. lumholtzi) was more sensitive than the temperate D. magna. Therefore, it could be used as an indicator for toxicity assessment in tropical environments. The presence of diazinon in water bodies can be associated with significant risk to aquatic organisms.
\end{abstract}

\section{Introduction}

In recent decades, most of the developed countries are shifting toward a chemical-free agriculture, also known as "organic" agriculture/farming, or in other words, decreasing the use of pesticides $[1,2]$. This has resulted in substantial improvements in agronomic practices guided by stringent legislations and in the quality of natural water bodies, that is, less risk to the aquatic lives $[1,2]$. Most of the developing countries in the tropical regions are increasing their use of pesticides and fertilizers as they become wealthier [3]. As a result, the concentration of pesticides in tropical environments has constantly increased, causing a decline in species diversity. Although pesticides have certain beneficial effects for agricultural crops, their use can cause a wide range of toxic effects on different nontarget organisms [4].

Diazinon (O,O-diethyl-O-[2-isopropyl-6-methyl-4pyrimidinyl] phosphorothioate) is a nonsystemic organophosphate insecticide. It was commonly used for insert control in agricultural crops $[4,5]$. The toxicity of diazinon results from inhibiting the enzyme acetylcholinesterase
(AChE), leading to the accumulation of neurotransmitters and altered signal transmission in chemical synapses [6]. In the domestic and international markets, there are more than 500 registered products that contain diazinon as the active substance [4]. Due to its widespread use, diazinon is frequently found in freshwater ecosystems [7]. In a recent study, Montuori et al. [7] reported that diazinon is prevalent in aquatic systems all over Europe, with the highest concentration recorded to be $785 \mathrm{ng} \cdot \mathrm{L}^{-1}$ in the Ebro River, Spain. Moreover, high concentrations of diazinon up to $1.5 \mu \mathrm{g} \cdot \mathrm{L}^{-1}$ have been found in urban waterways in California [8]. In recent decades, diazinon has been widely used in tropical regions [9]. However, pesticide laws and regulations have not been implemented adequately in these regions despite its heavy applications. The toxic effects of diazinon are available in the literature for the temperate cladoceran $D$. magna. However, the toxic effects of diazinon on tropical zooplanktons have not been well documented and studied in the literature.

Diazinon generates high acute toxicity to a wide variety of aquatic organisms, leading to a wide range of sublethal 
biochemical effects, damage to specific target organs and tissues, and adverse ecological impacts. The toxicity of diazinon has extensively studied in fish [4, 9-11] and crustaceans $[6,12,13]$, and it has been reported to be moderately toxic to early life stages of zebrafish [4]. The $96 \mathrm{~h} \mathrm{LC}_{50}$ values ranging from 0.32 to $1.53 \mathrm{mg} \cdot \mathrm{L}^{-1}$ for larval and from 2.2 to $10.3 \mathrm{mg} \cdot \mathrm{L}^{-1}$ for adult of several fish have already been recorded [10]. Yen et al. [11] reported that diazinon lowers larval swimming activity and inhibits AChE activity in zebrafish, as well as an increase in the Hsp70 content. In cladocerans, diazinon at the concentration from 0.18 to $0.30 \mu \mathrm{g} \cdot \mathrm{L}^{-1}$ caused adverse effects on the survival of $D$. magna $[6,14]$. These diazinon concentrations have been reported to cause a decrease in mean total young per female, mean brood size, and rate of population increase (RPI) and development of $D$. magna. Only the concentration above $0.25 \mu \mathrm{g} \cdot \mathrm{L}^{-1}$ caused a delay in the time to first reproduction [14]. Toxicokinetic and toxicodynamic models of diazinon and its by-product 2-isopropyl-6-methyl-4-pyrimidinol in crustacean species were investigated by Kretschmann et al. [15]. Results suggested that the oxidative dearylation of diazinon to pyrimidinol is a crucial cellular detoxification step which is catalyzed by the enzyme P450 [15]. However, most ecotoxicological studies use the temperate cladoceran $D$. magna as an ecotoxicological model; the toxicity of insecticide on tropical zooplankton species has not been examined to the same extent [16].

In this study, an acute $48 \mathrm{~h}$ assay and a chronic 14-day assay were performed to study the effects of diazinon on two cladoceran species. The toxicity of diazinon to early life stages of the temperate species $D$. magna was tested, and the toxicity on $D$. magna was compared to that on the tropical species $D$. lumholtzi. The results will provide baseline information to establish the benchmark for organophosphate insecticides in tropical waters.

\section{Materials and Methods}

2.1. Chemicals. Diazinon (O,O-diethyl-O-[2-isopropyl-6methyl-4-pyrimidinyl] phosphorothioate) was purchased from Sigma-Aldrich. Stock solutions of $1 \mathrm{mM}$ were prepared by diluting in dimethyl sulfoxide (DMSO) prior to the experiment and kept at $4^{\circ} \mathrm{C}$.

2.2. Test Organisms. Two cladocerans species were used in the present study: D. lumholtzi was isolated from a fish pond in the north of Vietnam. D. magna was obtained from MicroBioTest Inc. (Belgium). Both daphnids were grown in $1 \mathrm{~L}$ beakers filled with COMBO medium [17] and kept at a temperature of $25 \pm 1^{\circ} \mathrm{C}$ under a light: dark cycle of $12 \mathrm{~h}: 12 \mathrm{~h}$. The animals were fed with microgreen alga (Chlorella sp.) and a 1:1:1 mixture of yeast, cerrophyl, and trout chow digestion (YTC) [18]. The food and culture medium were renewed every two days.

2.3. Acute Toxicity Assay. The acute immobilization test was performed according to Protocol 202 of the Organization for the Economical Cooperation and Development [19]. This assay was performed to evaluate the sensitivity of the species and to establish the range of concentrations to be used in chronic assays. Briefly, Daphnia neonates $(<24 \mathrm{~h}$ old) were maintained in $50 \mathrm{~mL}$ beakers containing $30 \mathrm{~mL}$ COMBO medium spiked with diazinon at a concentration range of 0 , $0.5,1,2,5$, and $10 \mu \mathrm{g} \cdot \mathrm{L}^{-1}$. In each exposure concentration, 15 neonates were exposed per concentration of diazinon and blank control. All test exposures were prepared in triplicate. The test containers were placed at a controlled temperature of $25 \pm 1^{\circ} \mathrm{C}$ under a light: dark cycle of $14 \mathrm{~h}: 10 \mathrm{~h}$ during $48 \mathrm{~h}$ of incubation. The assessed response for this assay was the immobility or death of the cladocerans. The criterion for test acceptance was a survival rate greater than or equal to $90 \%$ in the control group. Finally, the mortality data recorded at the end of the toxicity tests $(48 \mathrm{~h})$ were used to determine the median lethal concentration $\left(48 \mathrm{~h} \mathrm{LC}_{50}\right)$.

2.4. Chronic Toxicity Assay. Based on the acute toxicity results and environmentally relevant concentrations of diazinon in previous studies $[7,8]$, daphnids were exposed during 14 days to the following sublethal diazinon concentrations: 0 (control), $0.05,0.1,0.2,0.5$, and $1.0 \mu \mathrm{g} \cdot \mathrm{L}^{-1}$. The reproduction test was conducted according to the standard protocol described in APHA [20] with minor modifications. Briefly, neonates of less than $24 \mathrm{~h}$ old were individually incubated in $50 \mathrm{~mL}$ beakers containing $20 \mathrm{~mL}$ control medium or exposed to diazinon concentrations. Diazinon concentrations and food (a mixture of green algae Chlorella sp., at a density of $5 \times 10^{6}$ cells $\cdot \mathrm{mL}^{-1}$, and YTC) were renewed every two days. The survival, reproduction (fecundity), time for the first reproduction, total number of neonates per female, number of broods, and brood size were recorded daily. The body length of parent daphnids was measured at the end of the experiment.

2.5. Statistical Analysis. The $48 \mathrm{~h}$ median lethal concentrations $\left(48 \mathrm{~h} \mathrm{LC}_{50}\right)$ were predicted by probit analysis as previously reported by Stephan [21]. The rate of population increase (RPI) was calculated according to the method suggested by Euler-Lotka [22]: $\sum \mathrm{e}^{-\mathrm{rx}} l_{\mathrm{x}} \mathrm{m}_{\mathrm{x}}=1$, where $l_{\mathrm{x}}=$ the proportion of surviving to age $x, m_{\mathrm{x}}=$ age-specific fecundity, and $x=$ time in days. All the calculations were based on 14day experiments [23]. The differences between treatment groups and controls were determined through one-way analysis of variance (ANOVA). Significant differences $(p<0.05)$ were distinguished by using Dunnet's test method. All data are presented as median \pm SD.

\section{Results and Discussion}

3.1. Acute Toxicity. No mortality occurred in the control during the experimental time of acute test. The highest tested concentration of diazinon resulted in $100 \%$ mortality of both daphnids. However, diazinon showed higher toxicity to $D$. lumholtzi. The $48 \mathrm{~h} \mathrm{LC}_{50}$ values of diazinon for D. magna and D. lumholtzi under the tested experimental conditions, at $95 \%$ confidence interval, were 4.63 and $3.41 \mu \mathrm{g} \cdot \mathrm{L}^{-1}$, respectively.

The toxic effects of pesticides on aquatic organisms are often investigated using the temperate $D$. magna under 
laboratory conditions. However, there is still little understanding about the acute and chronic effects of diazinon on crustaceans, especially to species that originated from tropical regions. The $48 \mathrm{~h} \mathrm{LC}_{50}$ values of diazinon reported in this study were in the range with the $48 \mathrm{~h} \mathrm{LC}_{50}$ values reported for nauplius of copepod Eodiaptomus $\left(48 \mathrm{~h} \mathrm{LC}_{50}=2.8 \mu \mathrm{g} \cdot \mathrm{L}^{-1}\right.$ ), Mesocyclops ( $\left.48 \mathrm{~h} \mathrm{LC}_{50}=2.9 \mu \mathrm{g} \cdot \mathrm{L}^{-1}\right)$, and Thermocyclops $(48 \mathrm{~h}$ $\left.\mathrm{LC}_{50}=4.1 \mu \mathrm{g} \cdot \mathrm{L}^{-1}\right)$ [24]. However, the values were lower than the $48 \mathrm{~h} \mathrm{LC}_{50}$ values for adults of Eodiaptomus $\left(48 \mathrm{~h} \mathrm{LC}_{50}=\right.$ $\left.46.8 \mu \mathrm{g} \cdot \mathrm{L}^{-1}\right)$, Mesocyclops (48h $\left.\mathrm{LC}_{50}=30.6 \mu \mathrm{g} \cdot \mathrm{L}^{-1}\right)$, and Thermocyclops ( $48 \mathrm{~h} \mathrm{LC}_{50}=40.2 \mu \mathrm{g} \cdot \mathrm{L}^{-1}$ ) [24], or higher than $48 \mathrm{~h} \mathrm{LC}_{50}$ values for other cladocerans such as Ceriodaphnia dubia $\left(48 \mathrm{~h} \mathrm{LC}{ }_{50}=0.21 \mu \mathrm{g} \cdot \mathrm{L}^{-1}\right)$ [12]. Results from acute assays documented higher sensitivity of tropical $D$. lumholtzi neonates to diazinon when compared to the temperate $D$. magna. From a practical application perspective, these results clearly showed that the D. lumholtzi may serve as a suitable surrogate for the temperate species D. magna, that is, as a toxicity indicator species, under tropical conditions.

3.2. Chronic Toxicity. The effects of sublethal diazinon concentrations on the survival and reproduction of $D$. magna and D. lumholtzi during 14 days of incubation are shown in Table 1 and Figure 1. The survival of both daphnids decreased with increasing concentrations of diazinon during the 14-day test. Significant decreases in life history responses were observed for D. magna and D. lumholtzi when exposed to diazinon. Both daphnids grew well in the control incubation (the length of D. magna and D. lumholtzi increased up to 4.1 and $2.4 \mathrm{~mm}$, respectively, at the end of the experiment). All individuals in the control survived throughout the experimental period (14 days) and produced numerous offspring $(27.4 \pm 3.6$ juveniles per D. magna and $18.2 \pm 2.1$ per D. lumholtzi).

Diazinon caused significant effects and dose-dependent increases on the reproduction (number of broods per female) of both daphnids (Table 1). For D. magna, diazinon at the concentration up to $0.1 \mu \mathrm{g} \cdot \mathrm{L}^{-1}$ or higher resulted in a significant decrease in reproduction (number of broods per female), while for D. lumholtzi, a significant reduction of reproduction was recorded from the lowest concentration tested $\left(0.05 \mu \mathrm{g} \cdot \mathrm{L}^{-1}\right)$. The reproduction of both daphnids was significantly delayed $(p<0.05)$, from 6.5 days for the control to 9.6 days for $D$. magna (as the diazinon concentration up to $0.1 \mu \mathrm{g} \cdot \mathrm{L}^{-1}$ or higher), and from 3.5 days in the control to 5.4 days for $D$. lumholtzi (as the diazinon concentration up to $0.05 \mu \mathrm{g} \cdot \mathrm{L}^{-1}$ or higher) (Table 1). The results of both tested species indicated that the number of neonates born per female significantly declined at the diazinon concentration of $0.1 \mu \mathrm{g} \cdot \mathrm{L}^{-1}$ or higher (Table 1 ). The mean body length significantly decreased in those daphnids (as the diazinon concentration up to $0.2 \mu \mathrm{g} \cdot \mathrm{L}^{-1}$ or higher) within the 14-day test period, from 4.1 to $3.1 \mathrm{~mm}$ and from 2.4 to $1.9 \mathrm{~mm}$ in $D$. magna and D. lumholtzi, respectively.

The results of the life-response history of both $D$. magna and $D$. lumholtzi species. Exposure to sublethal concentrations of diazinon under laboratory conditions showed that diazinon significantly reduced the number of offspring produced per female and delayed in the age at first brood. The obtained results are in agreement with previous observations which showed a decrease in the mean offspring production and suppression of growth in D. magna or Ceriodaphnia dubia following exposure to diazinon [12, 14, 25].

The results from the chronic assay showed that D. lumholtzi was a sensitive species to diazinon. Sánchez et al. [25] suggested that crustaceans are closely related to insects, more than other invertebrates. Hence, they are more sensitive to pesticides than other invertebrates. Modra et al. [5] indicated that the toxicity of diazinon is affected by many factors such as the biotransformation ability of the organism itself, water temperature, presence of other pollutants, and other nonidentified environmental variables. On the other hand, by using a toxic kinetic and dynamic model for studying diazinon toxicity, Kretschmann et al. [13] suggested that the sensitivity of test species to diazinon may depend on the detoxification ability of diazinon and diazoxon (a toxic metabolite of diazoxon). These authors revealed that, when compared to D. magna, the amphipod crustacean Gammarus pulex is less sensitive to diazinon because the detoxification of diazinon and diazoxon is six times faster which in turn causes less damaging effects. The authors also suggested that mechanistic-based effect models should be used to explain the actual causes, effects, and the minor differences among different aquatic invertebrates [13].

\subsection{Effects of Diazinon on Rate of Population Increase.} The effects of diazinon on the RPI are shown in Figure 2. Diazinon concentrations equal and/or greater than $0.1 \mu \mathrm{g} \cdot \mathrm{L}^{-1}$ significantly reduced the RPI of both daphnids during the 14-day chronic test $(p<0.05)$. It can be observed that both daphnids exposed to diazinon showed a nearly similar trend during the 14-day chronic test. In natural environments, diazinon is known to cause adverse effects on many zooplankton species including Daphnia, even at low concentrations (from 5.3 to $26.3 \mathrm{nM}$ ) [6, 15]. The RPI of the Daphnia population is an important indicator for prediction population trends. The survival rate, number of offspring per female, and age of fecundity are all crucial for the prediction [26]. A reduction in the RPI indicated chronic toxicant stress of pesticides on Daphnia [27].

Our results indicated that both test species were sensitive to diazinon and could be employed to predict the risk of insecticides. The present results clearly suggest that the growth rates of D. magna and D. lumholtzi in the control treatments were within the range reported in the literature $[25,26]$. In tropical countries, it is necessary to establish the benchmark for organophosphate insecticides. To minimize environmental risk associated with pesticides in tropical ecosystems, we strongly recommend further studies on short- and long-term toxic effects of organophosphate insecticides on different tropical groups of organisms.

\section{Conclusions}

The present study confirmed that diazinon poses significant risk to aquatic organisms, namely, nontarget Daphnia 
TABLE 1: Fecundity, survival, and body length of D. magna and D. lumholtzi after exposure to different concentrations of diazinon for 14 days.

\begin{tabular}{|c|c|c|c|c|c|}
\hline Diazinon $\left(\mu \mathrm{g} \cdot \mathrm{L}^{-1}\right)$ & $\begin{array}{c}\text { Number of broods } \\
\text { per female }\end{array}$ & $\begin{array}{l}\text { Age at first } \\
\text { reproduction (days) }\end{array}$ & $\begin{array}{c}\text { Number of offspring } \\
\text { per female }\end{array}$ & $\begin{array}{c}\text { Longevity } \\
\text { (days) }\end{array}$ & $\begin{array}{l}\text { Length } \\
(\mathrm{mm})\end{array}$ \\
\hline \multicolumn{6}{|l|}{ D. magna } \\
\hline CT & $4.9 \pm 0.2$ & $6.5 \pm 0.3$ & $27.4 \pm 3.6$ & 14 & $4.1 \pm 0.05$ \\
\hline 0.05 & $4.5 \pm 0.1$ & $7.2 \pm 0.2$ & $24.7 \pm 3.2$ & 14 & $4.0 \pm 0.07$ \\
\hline 0.1 & $3.2 \pm 0.2^{*}$ & $7.8 \pm 0.2^{*}$ & $19.6 \pm 4.3^{*}$ & 14 & $3.9 \pm 0.08$ \\
\hline 0.2 & $2.0 \pm 0.0^{*}$ & $8.6 \pm 0.3^{*}$ & $12.2 \pm 2.5^{*}$ & 14 & $3.8 \pm 0.04^{*}$ \\
\hline 0.5 & $1.8 \pm 0.1^{*}$ & $9.3 \pm 0.6^{*}$ & $3.7 \pm 4.6^{*}$ & 11 & $3.3 \pm 0.07^{*}$ \\
\hline 1 & $1.6 \pm 0.1^{*}$ & $9.6 \pm 0.3^{*}$ & $3.1 \pm 2.6^{*}$ & 10 & $3.1 \pm 0.09^{*}$ \\
\hline \multicolumn{6}{|l|}{ D. lumholtzi } \\
\hline CT & $4.2 \pm 0.3$ & $3.5 \pm 0.3$ & $18.2 \pm 2.1$ & 14 & $2.4 \pm 0.05$ \\
\hline 0.05 & $3.7 \pm 0.1^{*}$ & $3.4 \pm 0.5$ & $18.4 \pm 1.3$ & 14 & $2.4 \pm 0.06$ \\
\hline 0.1 & $3.6 \pm 0.1^{*}$ & $4.2 \pm 0.2^{*}$ & $16.2 \pm 1.5^{*}$ & 14 & $2.3 \pm 0.07$ \\
\hline 0.2 & $3.0 \pm 0.1^{*}$ & $4.7 \pm 0.4^{*}$ & $9.6 \pm 1.9^{*}$ & 11 & $2.0 \pm 0.05^{*}$ \\
\hline 0.5 & $2.5 \pm 0.2^{*}$ & $5.1 \pm 0.3^{*}$ & $5.4 \pm 1.3^{*}$ & 9 & $2.1 \pm 0.08^{*}$ \\
\hline 1 & $2.2 \pm 0.1^{*}$ & $5.4 \pm 0.2^{*}$ & $4.1 \pm 1.2^{*}$ & 6 & $1.9 \pm 0.05^{*}$ \\
\hline
\end{tabular}

Note. ${ }^{*} p<0.05$.

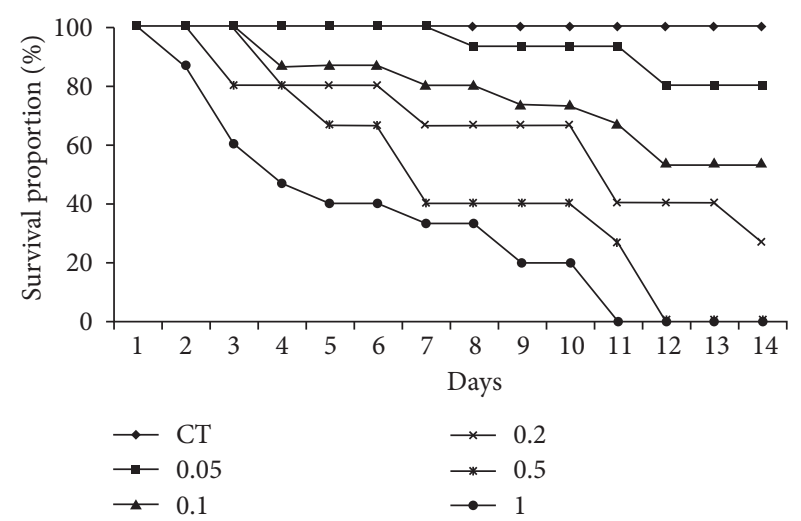

(a)

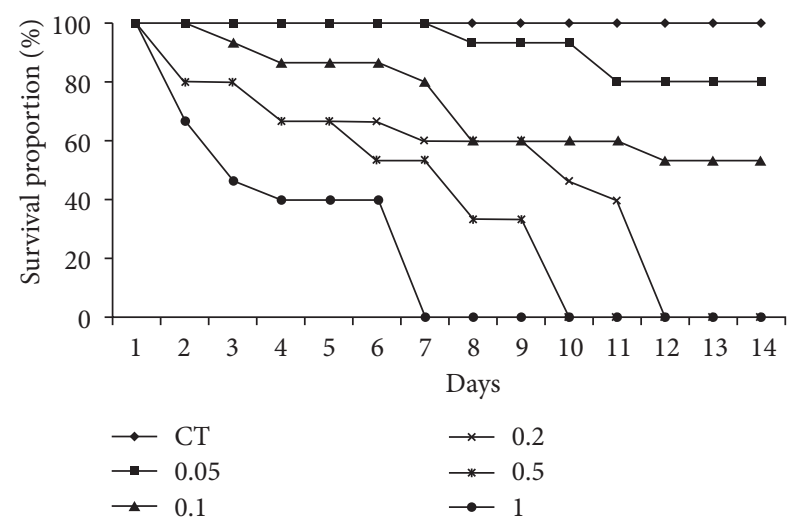

(b)

Figure 1: Survival results after exposure to different diazinon concentrations $\left(\mu \mathrm{g} \cdot \mathrm{L}^{-1}\right)$. (a) D. magna and (b) D. lumholtzi.

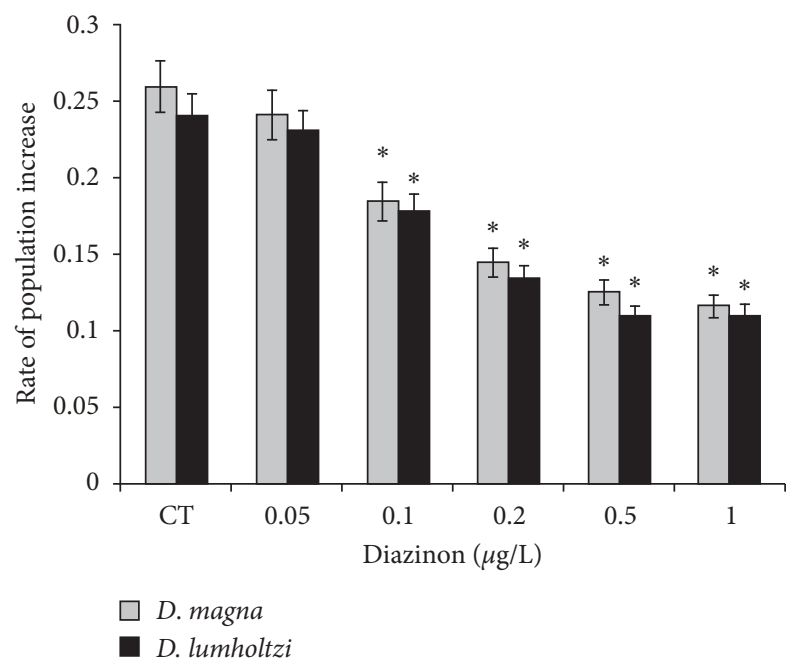

FIGURE 2: The effect of diazinon on the rate of population increase of Daphnia. * Significant difference with the control $(p<0.05)$. species. The population growth of D. magna and D. lumholtzi was adversely affected by diazinon after a chronic exposure period. Compared with D. magna, D. lumholtzi showed even higher sensitivity to diazinon in the acute test. The results of this study are important for prediction of toxic effects and environmental risk associated with insecticides. Further studies using additional organophosphate insecticides, different tropical test species, and test conditions are needed to assess the possible environmental risk associated with pesticides in tropical aquatic ecosystems.

\section{Data Availability}

The data used to support the findings of this study are available from the corresponding author upon request.

\section{Conflicts of Interest}

The authors declare that they have no conflicts of interest. 


\section{Acknowledgments}

The authors would like to thank Associate Professor ThanhSon Dao for his technical support.

\section{References}

[1] C. E. Handford, C. T. Elliott, and K. Campbell, "A review of the global pesticide legislation and the scale of challenge in reaching the global harmonization of food safety standards," Integrated Environmental Assessment and Management, vol. 11, no. 4, pp. 525-536, 2015.

[2] A. Tal, "Making conventional agriculture environmentally friendly: moving beyond the glorification of organic agriculture and the demonization of conventional agriculture," Sustainability, vol. 10, no. 4, p. 1078, 2018.

[3] F. Sanchez-Bayo and R. V. Hyne, "Comparison of environmental risks of pesticides between tropical and nontropical regions," Integrated Environmental Assessment and Management, vol. 7, no. 4, pp. 577-586, 2011.

[4] M. Velki, C. Di-Paolo, J. Nelles, T. B. Seiler, and H. Hollert, "Diuron and diazinon alter the behavior of zebrafish embryos and larvae in the absence of acute toxicity," Chemosphere, vol. 180, pp. 65-76, 2017.

[5] H. Modra, D. Vrskova, S. Macova et al., "Comparison of diazinon toxicity to embryos of Xenopus laevis and Danio rerio: degradation of diazinon in water," Bulletin of Environmental Contamination and Toxicology, vol. 86, no. 6, pp. 601-604, 2011.

[6] M. A. Zein, S. P. McElmurry, D. R. Kashian, P. T. Savolainen, and D. K. Pitts, "Toxic effects of combined stressors on Daphnia pulex: interactions between diazinon, 4-nonylphenol, and wastewater effluent," Environmental Toxicology and Chemistry, vol. 34, no. 5, pp. 1145-1153, 2015.

[7] P. Montuori, S. Aurino, A. Nardone, T. Cirillo, and M. Triassi, "Spatial distribution and partitioning of organophosphates pesticide in water and sediment from Sarno River and Estuary, Southern Italy," Environmental Science and Pollution Research, vol. 22, no. 11, pp. 8629-8642, 2015.

[8] H. C. Bailey, L. Deanovic, E. Reyes et al., "Diazinon and chlorpyrifos in urban waterways in Northern California, USA," Environmental Toxicology and Chemistry, vol. 19, no. 1, pp. 82-87, 2000.

[9] V. C. Nguyen, N. T. Phuong, and M. Bayley, "Sensitivity of brain cholinesterase activity to diazinon (BASUDIN 50EC) and fenobucarb (BASSA 50EC) insecticides in the airbreathing fish Channa striata (Bloch, 1793)," Environmental Toxicology and Chemistry, vol. 25, no. 5, pp. 1418-1425, 2006.

[10] V. Scheil, C. Kienle, R. Osterauer, A. Gerhardt, and H.-R. Köhler, "Effects of 3,4-dichloroaniline and diazinon on different biological organisation levels of zebrafish (Danio rerio) embryos and larvae," Ecotoxicology, vol. 18, no. 3, pp. 355-363, 2009.

[11] J. Yen, S. Donerly, E. D. Levin, and E. Linney, "Differential acetylcholinesterase inhibition of chlorpyrifos, diazinon, and parathion in larval zebrafish," Neurotoxicology and Teratology, vol. 33, no. 6, pp. 735-741, 2011.

[12] K. E. Banks, P. K. Turner, S. H. Wood, and C. Matthews, "Increased toxicity to Ceriodaphnia dubia in mixtures of atrazine and diazinon at environmentally realistic concentrations," Ecotoxicology and Environmental Safety, vol. 60, no. 1, pp. 28-36, 2005.
[13] A. Kretschmann, R. Ashauer, J. Hollender, and B. I. Escher, "Toxicokinetic and toxicodynamic model for diazinon toxicity - mechanistic explanation of differences in the sensitivity of Daphnia magna and Gammarus pulex," Environmental Toxicology and Chemistry, vol. 31, no. 9, pp. 2014-2022, 2012.

[14] A. Fernández-Casalderrey, M. D. Ferrando, and E. AndreuMoliner, "Chronic toxicity of diazinon to Daphnia magna: effects on survival, reproduction and growth," Toxicological and Environmental Chemistry, vol. 49, no. 1-2, pp. 25-32, 1995.

[15] A. Kretschmann, R. Ashauer, T. G. Preuss, P. Spaak, B. I. Escher, and J. Hollender, "Toxicokinetic model describing bioconcentration and biotransformation of diazinon in Daphnia magna," Environmental Science and Technology, vol. 45, no. 11, pp. 4995-5002, 2011.

[16] S. L. Ghose, M. A. Donnelly, J. Kerby, and S. M. Whitfield, "Acute toxicity tests and meta-analysis identify gaps in tropical ecotoxicology for amphibians," Environmental Toxicology and Chemistry, vol. 33, no. 9, pp. 2114-2119, 2014.

[17] S. S. Kilham, D. A. Kreeger, S. G. Lynn, C. E. Goulden, and L. Herrera, "COMBO: a defined freshwater culture medium for algae and zooplankton," Hydrobiologia, vol. 377, no. 1/3, pp. 147-159, 1998.

[18] US Environmental Protection Agency (US EPA), Methods for Measuring the Acute Toxicity of Effluents and Receiving Waters to Freshwater and Marine Organisms, EPA-821-R02-012, 5th edition, 2002.

[19] OECD, Daphnia sp. Acute Immobilization Test: OECD Guideline for Testing of Chemicals No. 202, Organization for the Economical Cooperation and Development (Publisher), Paris, France, 2004.

[20] American Public Health Association (APHA), Standard Methods for the Examination of Water and Wastewater, American Public Health Association, Washington DC, USA, 2005.

[21] C. Stephan, Methods for Calculating an LC50, Vol. 634, ASTM (American Society for Testing and Materials) Special Technical Publication, West Conshohocken, PA, USA, 1977.

[22] A. J. Lotka, "A natural population norm," Journal of the Washington Academy of Sciences, vol. 3, no. 241-248, pp. 289-293, 1913

[23] M. J. Villarroel, E. Sancho, M. D. Ferrando, and E. Andreu, "Acute, chronic and sublethal effects of the herbicide propanil on Daphnia magna," Chemosphere, vol. 53, no. 8, pp. 857-864, 2003.

[24] H. Takahashi, K. H. Chang, and T. Hanazato, "Acute toxicity of the insecticide diazinon and carbaryl to calanoid and cyclopoid copepoda (Eodiaptomus, Mesocyclops and Thermocyclops) in different life stages," Japanese Journal of Environmental Toxicology, vol. 9, no. 2, pp. 133-139, 2006.

[25] M. Sánchez, M. D. Ferrando, E. Sancho, and E. AndreuMoliner, "Evaluation of a Daphnia magna renewal life-cycle test method with diazinon," Journal of Environmental Science and Health, Part B, vol. 33, no. 6, pp. 785-797, 1998.

[26] E. Sancho, M. J. Villarroel, and M. D. Ferrando, "Assessment of chronic effects of tebuconazole on survival, reproduction and growth of Daphnia magna after different exposure times," Ecotoxicology and Environmental Safety, vol. 124, pp. 10-17, 2016.

[27] J. R. Sánchez-Ortíz, S. S. S. Sarma, and S. Nandini, "Comparative population growth of Ceriodaphnia dubia and Daphnia pulex (Cladocera) exposed to zinc toxicity," Journal of Environmental Science and Health, Part A, vol. 45, no. 1, pp. 37-41, 2010. 

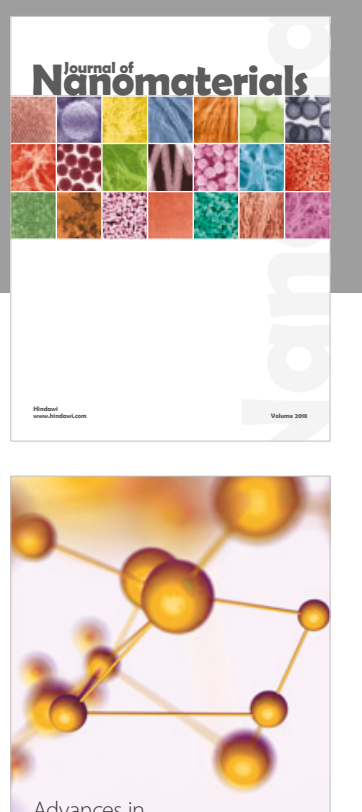

Physical Chemistry
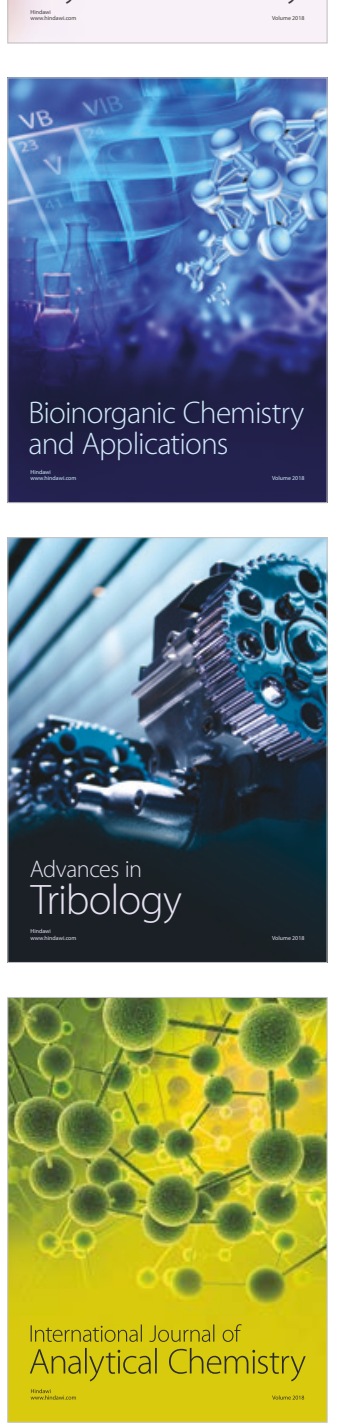

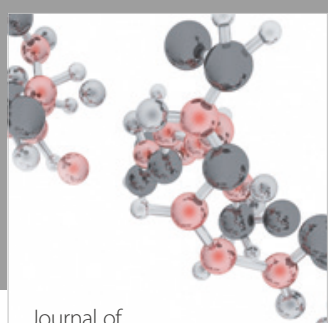

Analytical Methods

in Chemistry

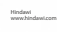

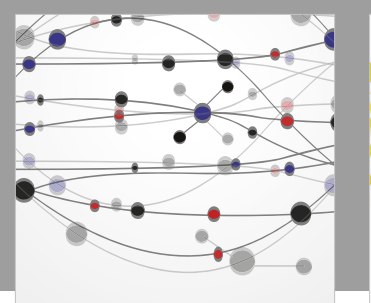

The Scientific World Journal

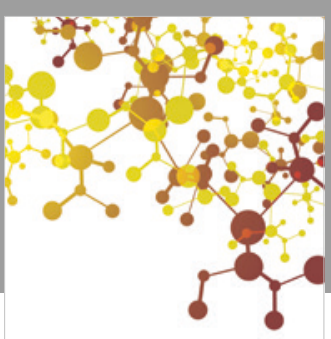

Journal of

Applied Chemistry
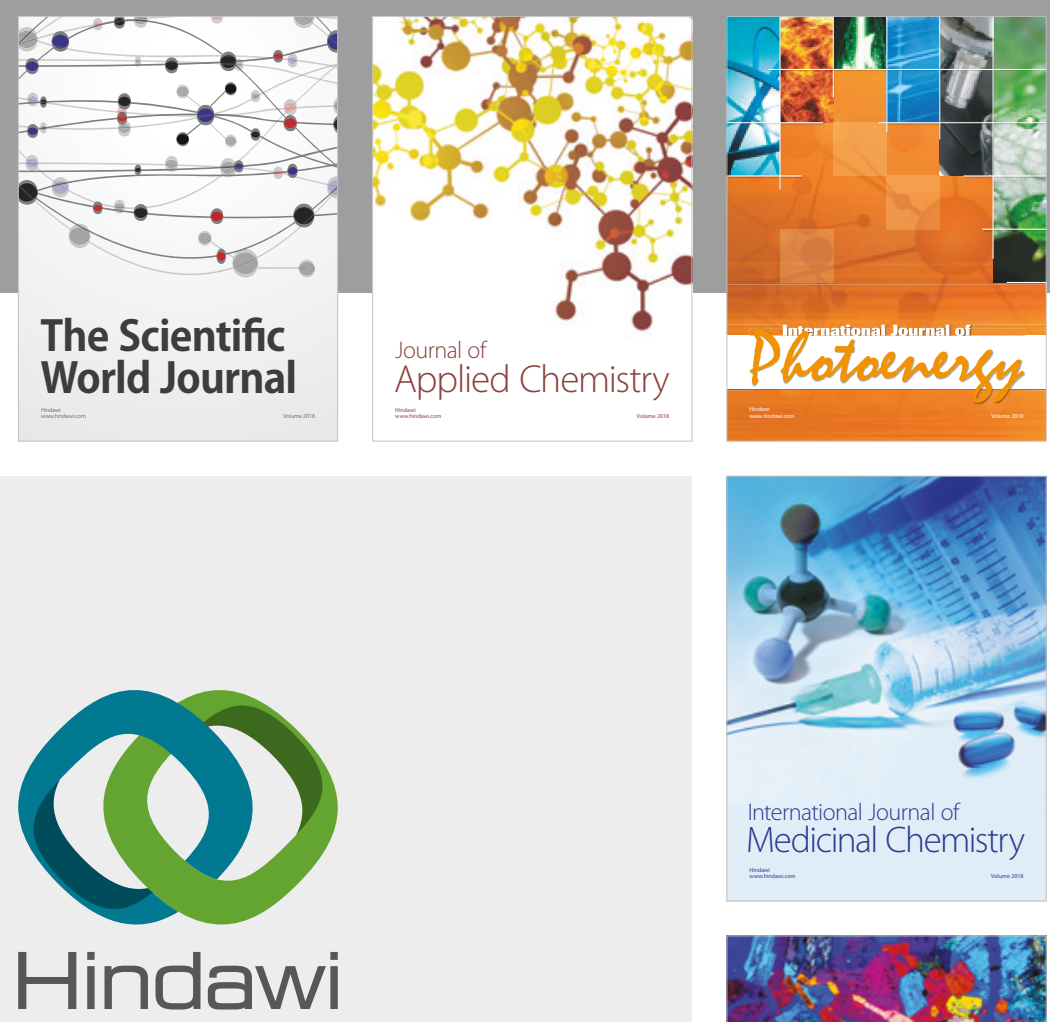

Submit your manuscripts at

www.hindawi.com
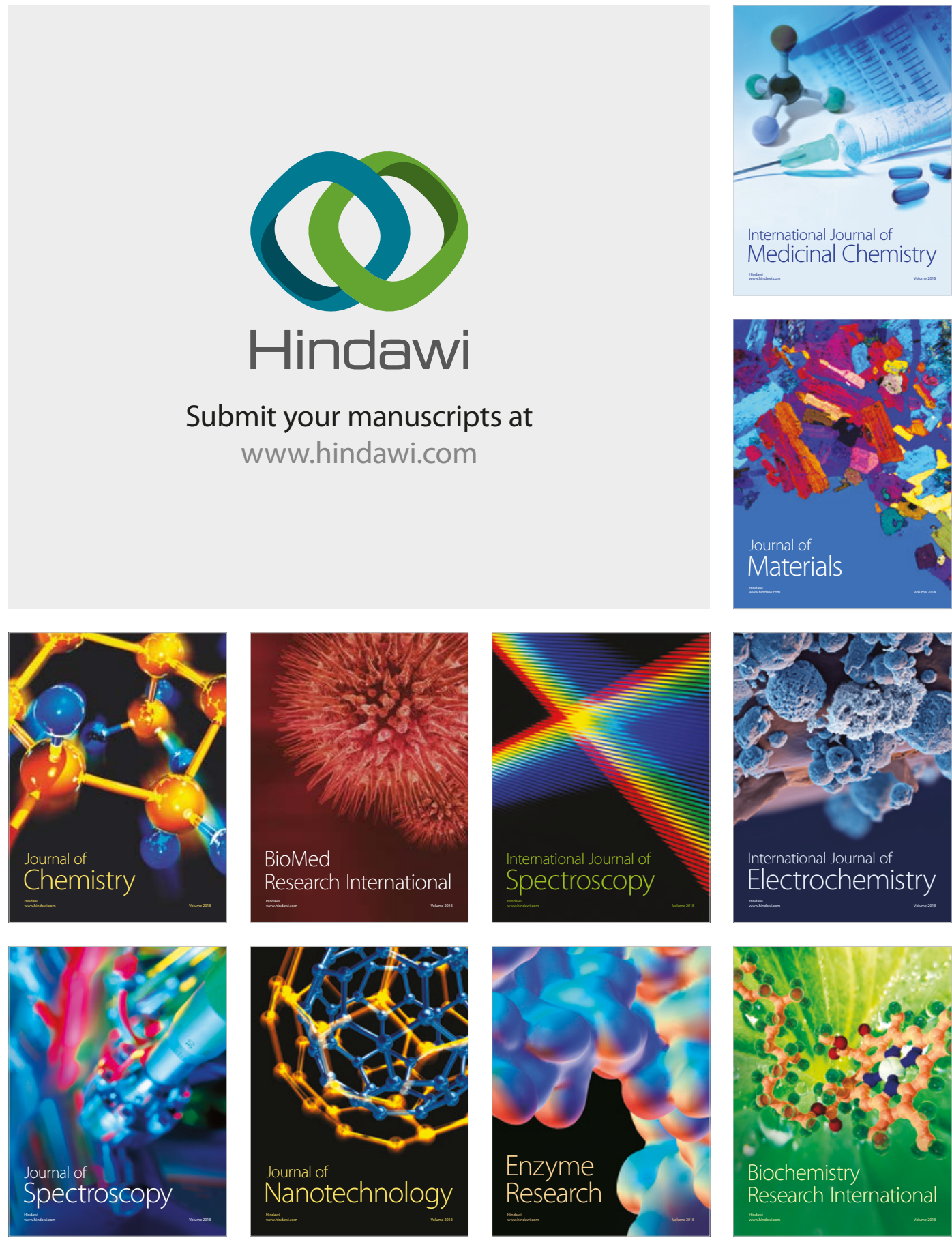
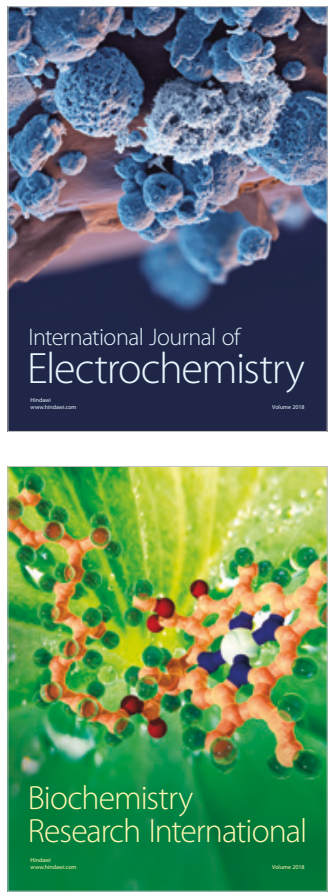